\title{
Papillary muscle approximation reduces systolic tethering forces and improves mitral valve closure in the repair of functional mitral regurgitation
}

Samantha Zhan-Moodie, BS, ${ }^{\mathrm{a}}$ Dongyang Xu, MS, ${ }^{\mathrm{a}}$ Kirthana Sreerangathama Suresh, MS, ${ }^{\mathrm{a}}$ Qi He, BS, ${ }^{\mathrm{a}}$ Daisuke Onohara, MD, PhD, ${ }^{a}$ Kanika Kalra, MD, ${ }^{a}$ Robert A. Guyton, MD, ${ }^{\text {a,b }}$ Eric L. Sarin, MD, ${ }^{a, c}$ and Muralidhar Padala, $\mathrm{PhD}^{\mathrm{a}, \mathrm{b}}$

\section{ABSTRACT}

Background: Undersizing mitral annuloplasty (UMA) to repair functional mitral regurgitation (FMR) lacks durability, as it forces leaflet coaptation without relieving the subleaflet tethering forces. In this biomechanical study, we demonstrate that papillary muscle approximation (PMA) before UMA can drastically relieve tethering forces and improve valve function, without the need for significant annular downsizing.

Methods: An ex vivo model of FMR was used, in which pig mitral valves were geometrically perturbed to induce FMR, and the repairs were performed. Nine pig mitral valves were studied in the following sequence: normal (baseline), FMR, true-sized annuloplasty to $30 \mathrm{~mm}$ (true-sized ring [TSR]), and undersized annuloplasty to $26 \mathrm{~mm}$ (down-sized ring [DSR]), along with concomitant PMA at both ring sizes. Mitral regurgitation, valve kinematics, and chordal forces were measured and compared among the groups.

Results: FMR geometry induced a mean regurgitant fraction of $16.31 \pm 7.33 \%$ compared with $\mathrm{\%} \%$ at baseline. TSR reduced the regurgitant fraction to $6.05 \pm 5.63 \%$, whereas DSR reduced it to $5.06 \pm 6.76 \%$. The addition of PMA before the use of these rings reduced the mean regurgitant fraction to $3.87 \pm 6.79 \%$ with the TSR (TSR + PMA) and $3.71 \pm 6.25 \%$ with the DSR (DSR + PMA). Mean peak anterior and posterior marginal chordal forces were elevated to $0.09 \pm 0.1 \mathrm{~N}$ and $0.12 \pm 0.1 \mathrm{~N}$, respectively, with FMR and were not reduced by annuloplasty of either sizes. The addition of PMA significantly reduced these forces to $0.23 \pm 0.02 \mathrm{~N}$ and $0.51 \pm 0.04 \mathrm{~N}$.

Conclusions: This biomechanical study demonstrates that PMA relieves tethering forces, and concomitantly with annuloplasty it mobilizes the leaflets to achieve physiological valve closure. Such a result could be achieved without the need for extensive annular downsizing. (JTCVS Open 2021;7:91-104)

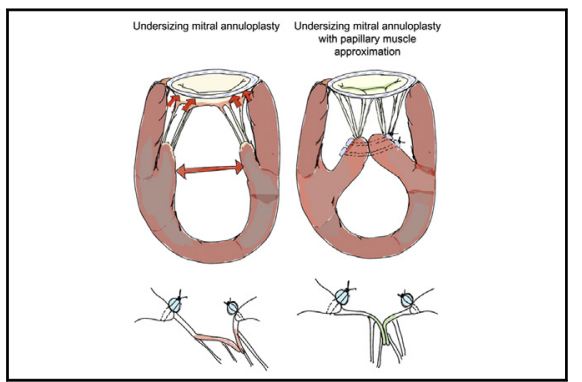

Papillary muscle approximation relieves tethering forces on the mitral valve and enables good correction of functional mitral regurgitation.

\section{CENTRAL MESSAGE}

Papillary muscle approximation

relieves mitral valve tethering

forces, enables better leaflet

mobility and closure, and elimi-

nates functional mitral

regurgitation.

\section{PERSPECTIVE}

Persistent systolic tethering of the mitral valve leaflets despite undersizing mitral annuloplasty is an established cause of repair failure and recurrent functional mitral regurgitation. In this study, we demonstrate that papillary muscle approximation when performed concomitantly with mitral annuloplasty can relieve the tethering forces, enable better leaflet mobility, and restore better coaptation. Adding this simple technique to annuloplasty may be useful in achieving a complete and durable repair.

See Commentaries on pages 105,107 , and 109

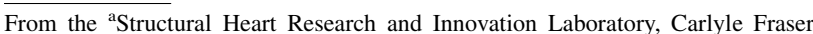
Heart Center, Emory University Hospital Midtown, Atlanta, Ga; ${ }^{\mathrm{b}}$ Division of Cardiothoracic Surgery, Department of Surgery, Emory University School of Medicine, Atlanta, Ga; and ${ }^{\mathrm{c}}$ Department of Cardiac Surgery, INOVA Heart and Vascular Institute, Fairfax, Va.

S.Z.-M. and D.X. contributed equally to this work and should be considered co-first authors.

This work was funded by grants from the National Heart, Lung and Blood Institute (NHLBI) (R01 HL135145, R01 HL133667, and R01 HL140325), INOVA Heart and Vascular Institute, and Carlyle Fraser Heart Center at Emory University Hospital Midtown.
Received for publication April 15, 2021; accepted for publication April 19, 2021; available ahead of print May 19, 2021.

Address for reprints: Muralidhar Padala, PhD, 380B Northyards Blvd, Atlanta, GA 30313 (E-mail: spadala@emory.edu).

2666-2736

Copyright (c) 2021 The Author(s). Published by Elsevier Inc. on behalf of The American Association for Thoracic Surgery. This is an open access article under the CC BY-NC-ND license (http://creativecommons.org/licenses/by-nc-nd/4.0/).

https://doi.org/10.1016/j.xjon.2021.04.008 


\section{Abbreviations and Acronyms \\ DSR $=$ down-sized ring \\ FMR $=$ functional mitral regurgitation \\ PMA $=$ papillary muscle approximation \\ TSR $=$ true-sized ring \\ $\mathrm{UMA}=$ undersizing mitral annuloplasty}

Video clip is available online.

Surgical repair of functional mitral regurgitation (FMR) is challenging, as current techniques lack durability. ${ }^{1-4}$ Undersizing mitral annuloplasty (UMA), ${ }^{5}$ which is the widely used repair option, reduces the mitral annular dimensions to draw the leaflets into the orifice for systolic overlap. Though coaptation is restored, annuloplasty does not relieve leaflet tethering and sometimes exacerbates it, resulting in a coaptation geometry that is unphysiological. ${ }^{6}$ The peak coaptation point after annuloplasty is still below the mitral annular plane, the posterior leaflet is immobilized, and the anterior leaflet hyperextends into coaptation. ${ }^{7-14}$ Such a configuration lacks durability, with persistent FMR shortly after surgery in $30 \%$ of the patients, and recurrence of moderate or greater FMR in $56 \%$ of the patients within 2 years, as shown in the CTSN trial. ${ }^{15}$ This high failure rate led to the recommendation that mitral valve replacement should be preferred over repair, even though the trial data demonstrated significantly better survival and left ventricular reverse remodeling in patients with a durable repair compared with those with mitral valve replacement. ${ }^{15}$

Subannular repairs have been hypothesized to relieve leaflet tethering and restore better coaptation, and a variety of techniques have been proposed and used clinically. Strut chordal cutting has been tried in sheep ${ }^{16}$ and in humans, ${ }^{17}$ but was found to abnormally redistribute the forces and increased the risk of chordal rupture and ventricular dysfunction. ${ }^{18}$ Leaflet augmentation was used to increase leaflet area, ${ }^{19}$ but the augmenting patch billowed, dehisced, or calcified. ${ }^{20}$ Papillary muscle hoisting toward the annulus was proposed, ${ }^{21}$ but its effect was focal and carried the risk of the muscle torsion. Papillary muscle approximation (PMA) was developed as a simpler approach, ${ }^{22}$ in which the muscles are laterally drawn together and fixed. This approach builds on the evidence that our group reported in human patients that lateral separation of the papillary muscles is a strong driver of FMR in heart failure. ${ }^{3,4}$ Despite some early successful attempts at adopting this technique into mainstream surgical practice, ${ }^{22,23}$ mechanistic data to support its further adoption remain lacking.

In this biomechanical study, we sought to measure the interactive effects of mitral annuloplasty when combined with PMA and papillary muscle approximation on mitral valve mechanics in FMR. We tested the hypothesis that PMA reduces tethering forces on the mitral valve in systole, enables better coaptation, and can achieve an overall better outcome without the need for extensive annular downsizing.

\section{METHODS \\ Informed Consent}

This research did not include any human subjects. Use of porcine tissues purchased from the slaughterhouse was approved by the environmental health and safety office of Emory University.

\section{Experimental Design}

The study design is depicted in Figure 1. Nine pig mitral valves were instrumented with miniature chordal force transducers, and studied in a sequence of experimental steps in a pulsatile mitral valve simulator. Valves were tested under the following conditions: (1) baseline mitral valve configuration, (2) disease/FMR configuration with annular dilatation and papillary muscle displacement, (3) repair with annuloplasty with a size 30 ring (true-sized ring [TSR]) and a size 26 ring (down-sized ring [DSR]), and (4) concomitant PMA with both annular ring sizes (TSR + PMA and DSR + PMA). Mitral valve function, geometry, and chordal forces were measured in each condition.

\section{Mitral Valve Selection and Preparation}

Pig hearts were purchased from Lampire Biological Products (Pipersville, $\mathrm{Pa}$ ), and the valves were sized using the technique described by Bothe and colleagues. ${ }^{11}$ Valves whose anterior leaflet matched a size 28 or 30 annuloplasty ring were selected (corresponding to an SL diameter of 23-25 mm). Mitral valves were extracted from these hearts with their annulus, leaflets, chordal apparatus and papillary muscles intact. Between 2 and $3 \mathrm{~mm}$ of left atrial tissue was left intact, and $20-30 \mathrm{~mm}$ of papillary muscle was left intact and wrapped in fabric to mount the valves into the simulator.

\section{Mitral Valve Simulator}

The left heart simulator is shown in Figure 2, A. The papillary muscles were mounted onto rods that could be spatially positioned within the ventricular chamber (Figure 2,B). Displacement was possible in the apical, posterior, and lateral directions with each papillary muscle (Figure 2, $C$ 1-3). Left atrial tissue extending from the mitral annulus was sutured onto a D-shaped frame, and an adjustable annuloplasty ring was sutured onto the valve annulus (Figure $3, A-C$ ). The ring can be adjusted using a handle from outside the simulator. The similarities between the designed annular ring and the commercial Edwards annuloplasty ring sizers (Edwards Lifesciences, Irvine, Calif) were confirmed (Figure E1). The valve was then mounted into the simulator consisting of an acrylic left atrium and left ventricle, connected in a closed circuit. A linear actuating pump with a viscoelastic impedance (Superpump; Vivitro Labs, London, Ontario, Canada) was connected to the left ventricle and programmed to generate physiological left ventricular pressures. Saline $(0.9 \%)$ served as the working medium in this flow loop. The simulator was instrumented with pressure transducers (Utah Medical, Salt Lake City, Utah) to measure left atrium, left ventricle, and aortic pressures and with 2 electromagnetic flow probes (Carolina Medical Electronics, East Bend, NC) to measure left heart inflow and outflow. Data were streamed to an acquisition system 
HYPOTHESIS: Does addition of papillary muscle approximation to annuloplasty improve mitral valve biomechanics and closure dynamics?

\section{METHODS}

\section{Ex vivo model of functional mitral} regurgitation

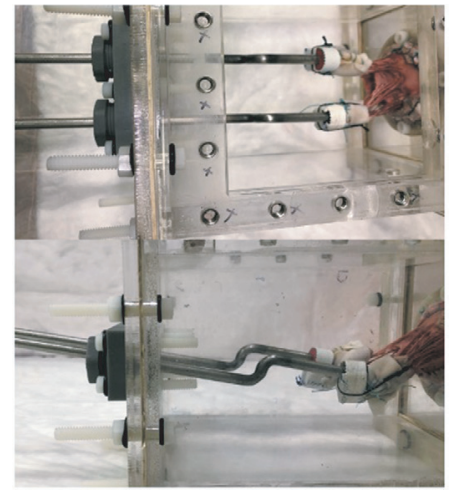

\section{RESULTS}

Concomitant papillary muscle approximation reduces regurgitation

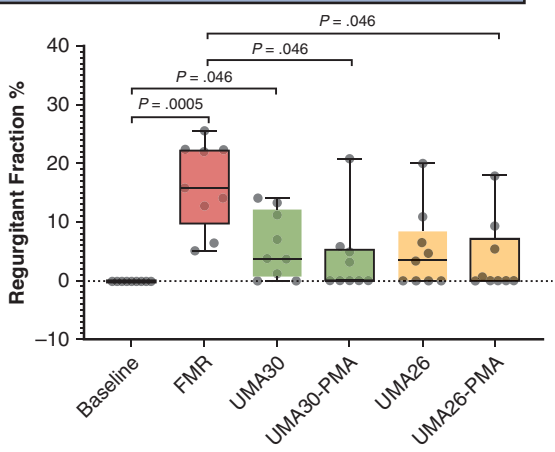

Baseline

Functional mitral regurgitation $30 \mathrm{~mm}$ annuloplasty

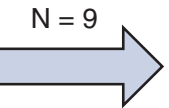

$26 \mathrm{~mm}$ annuloplasty

$30 \mathrm{~mm}$ annuloplasty with papillary muscle approximation

$26 \mathrm{~mm}$ annuloplasty with papillary muscle approximation
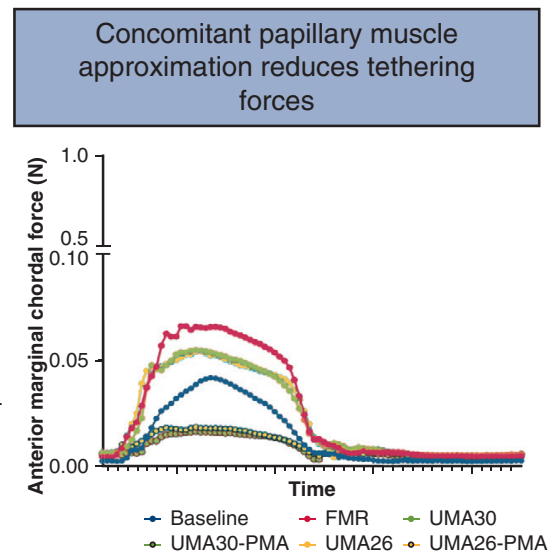

Hemodynamics
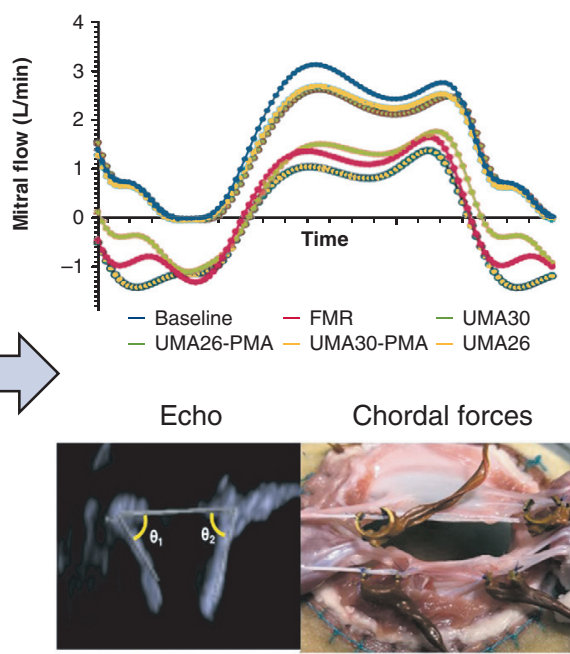

IMPLICATIONS: Addition of papillary muscle approximation relieves tethering forces on the mitral valve leaflets in systole and enables better coaptation in an ex vivo model of functional mitral regurgitation

FIGURE 1. Papillary muscle approximation reduces the ventricular tethering forces and restores physiological leaflet mobility and systolic coaptation when used concomitantly with undersizing mitral annuloplasty in the repair of functional mitral regurgitation. FMR, Functional mitral regurgitation; $U M A$, undersizing mitral annuloplasty; $P M A$, papillary muscle approximation.

(IX408; iWorx, Dover, NH), visualized and stored with Labscribe (iWorx), and analyzed with a custom MATLAB code.

\section{Baseline Valve Configuration}

The baseline/healthy configuration was defined as an annular size equivalent to a size 28 or 30 annuloplasty ring. Physiological papillary muscle location was determined in 2 steps. First, looking from the left atrium through the mitral orifice, the papillary muscles were positioned with their tips aligned with the commissures of the valve in the left-right axis, and were positioned such that they are midway between the anterior and posterior annulus in the top-bottom axis. Then, looking sideways at the valve, the papillary muscles were moved basally or apically until the commissural chordae were slightly taut.

\section{FMR Configuration}

To induce FMR, mitral valve geometry was perturbed by dilating the mitral annulus and displacing the papillary muscles. The annulus was dilated by expanding the adjustable annular ring until the dimensions matched that of a 36-mm annuloplasty sizer (corresponding to an SL diameter of $30 \mathrm{~mm}$ ). The papillary muscles were then displaced by $10 \mathrm{~mm}$ each in the apical, lateral, and posterior directions. These geometric perturbations tethered the mitral valve and caused FMR. 


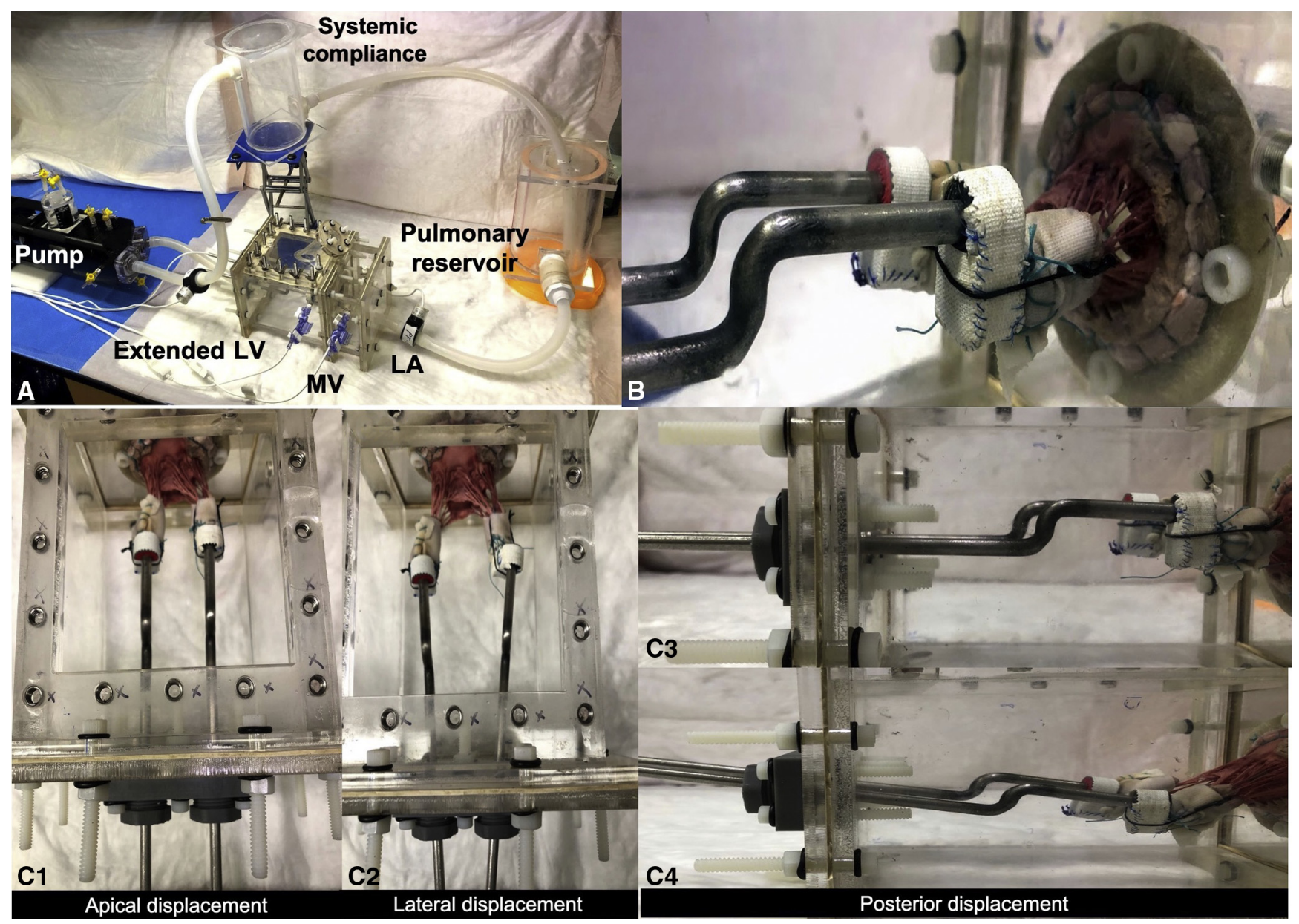

FIGURE 2. A, Photograph of the pulsatile left heart simulator used in this study, consisting of an acrylic left heart model with a native pig mitral valve, with the model placed in a closed flow loop. This setup is connected to a programmable pump to generate physiological pressures and flows through the circuit. B, Ventricular view of the pig mitral valve mounted into this acrylic model. The annulus is sutured onto the D-shaped ring, and the papillary muscles are mounted onto rods whose spatial position can be altered. C, Different configurations of the mitral valve, with apical, lateral, and posterior displacement of the papillary muscles. $L V$, Left ventricle; $M V$, mitral valve; $L A$, left atrium.

\section{Annuloplasty}

TSR and DSR mitral annuloplasty were performed by adjusting the ring size to either match the native annular size or reduce it beyond the native size. True-sizing was performed such that the dimensions of the annulus matched a size 30 annuloplasty ring. Undersizing was performed such that the dimensions of the annulus matched a size 26 annuloplasty ring.

\section{PMA}

PMA was performed by laterally drawing the muscles together, without moving them in any other plane. This was performed with both the TSR and DSR.

\section{Hemodynamics and Valve Kinematics}

Hemodynamic conditions were maintained at a heart rate of $70 \mathrm{bpm}$ and a transmitral pressure of $100 \mathrm{~mm} \mathrm{Hg}$ throughout the study. Pressure and flow data were averaged over 10 consecutive cardiac cycles. Regurgitant volume was calculated by integrating the negative part of the mitral flow curve; forward stroke volume, by integrating the positive part of the mitral flow curve; and total stroke volume, by monitoring the displacement of the pump head. The regurgitant fraction was calculated as the ratio of the regurgitant volume to the total stroke volume. Two-dimensional echocardiography was performed using a Z6Ms transesophageal echo probe on an Acuson SC2000 prime system (Siemens Healthineers, Malvern, $\mathrm{Pa}$ ) to assess the mitral valve kinematics and geometry. Using a long-axis view of the mitral valve, leaflet excursion angles, coaptation length, and tenting height were measured. Leaflet excursion angles were measured as the difference in the angle between the mitral annulus and the tip of the mitral leaflets in diastole and systole. In systole, because the leaflet would bend at the strut chordal insertion, a line connecting the annulus to the tip of the leaflet was used as proposed by Bothe and colleagues. ${ }^{11}$ Coaptation length was measured as length of overlap between the leaflets in systole. Tenting height was measured as the distance from the annulus to the point of leaflet coaptation in systole.

\section{Chordal Forces}

Forces were measured on the marginal and strut chordae tendineae on both mitral leaflets. Miniature custom-built strain gauge force transducers ${ }^{18}$ were developed (Figure 3, D 1-2) that could be mounted onto each chord to measure the forces in synchrony with hemodynamics. The transducer consists of a $\mathrm{C}$-shaped brass ring, with a $350 \Omega$ strain gauge mounted onto the inside and outside of the $\mathrm{C}$ ring and connected to a Wheatstone bridge circuit. Before the experiment, the transducers were calibrated with weights, and the linearity of transducer response was 


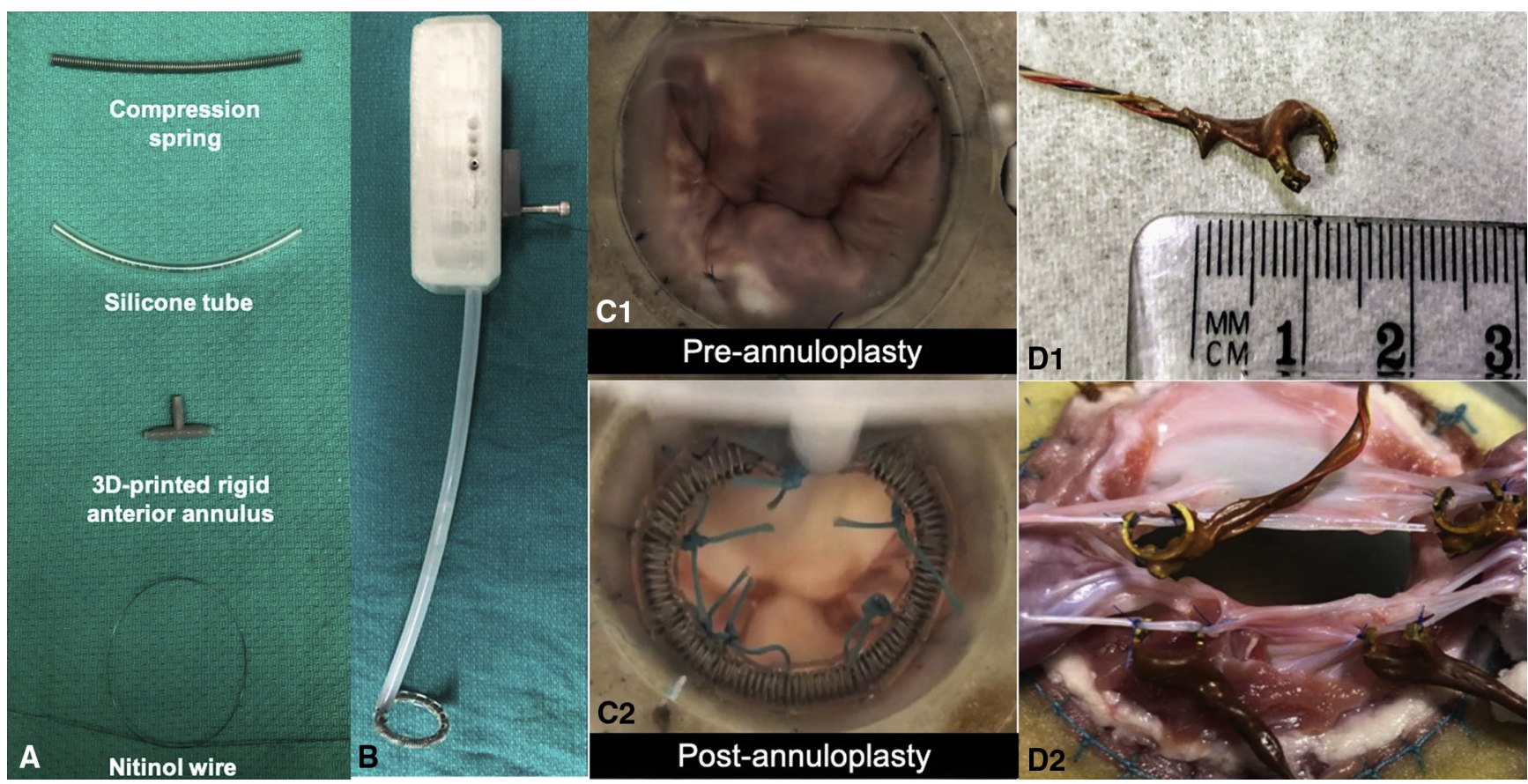

FIGURE 3. A, Deconstructed components of the adjustable annuloplasty ring. B, The adjustable annuloplasty ring mounted onto a 3-dimensional printed catheter to enable its size adjustment outside the pulsatile flow loop. C, Surgeon's view of the mitral valve in the flow loop, with and without the annuloplasty ring. D, Miniature force transducers developed to measure chordal forces. A transducer is shown to depict its size, and a photograph with transducers mounted onto the marginal and strut chordae is shown. 3D, 3-dimensional.

confirmed. The transducers were then sutured to the marginals and the strut chords of both leaflets emerging from the posteromedial papillary muscle using 6-0 Prolene. The C-ring wires were externalized from the simulator, and the force data were streamed to a computer and visualized using StrainSmart 8000 software (Micro-Measurements, Raleigh, NC).

\section{Data Analysis and Statistical Methods}

Statistical tests were performed using Prism 8.0 (GraphPad Software, San Diego, Calif). Sample size was estimated using pre hoc power analysis to test the hypothesis that the tenting area would be at least $25 \%$ smaller after PMA compared with the disease condition, with $85 \%$ power and an $\alpha$ value of 0.05 . Previous studies in this experimental model that we have reported were used for the standard deviation. All data were tested for normality using the Shapiro-Wilk normality test. Data following a normal distribution are represented as mean \pm standard deviation, and non-normally distributed data are represented as median with interquartile range (IQR). One-way ANOVA was performed, followed by a multiple comparison test with a repeated-measures test with Bonferroni correction or with Friedman's test. Statistical significance was set at $P<.05$.

\section{RESULTS}

The results are graphically depicted in Figures 4-6, with groupwise comparisons with corresponding $P$ values depicted in Table 1 . The results are orally narrated in Video 1.

\section{Mitral Valve Hemodynamics}

PMA eliminated the regurgitation, as depicted in Figure 4, A. At baseline, none of the valves had regurgitation. On dilating the annulus and displacing the papillary muscle (FMR), the mean regurgitant fraction was increased to $16.31 \pm 7.33 \%$ (median, $15.76 \%$; IQR, $12.87 \%$ $22.36 \% ; P=.0005)$. On implanting the annuloplasty ring and downsizing it to $30 \mathrm{~mm}$ (UMA-30), the mean regurgitant fraction decreased to $6.05 \pm 5.63 \%$ (median, $3.84 \%$; IQR, $1.22 \%-11.28 \%$ ). Further downsizing to $26 \mathrm{~mm}$ (UMA-26) resulted in a mean regurgitant fraction of $5.06 \pm 6.76 \%$ (median, 3.42\%, IQR, 0\%-6.59\%). Adding PMA to UMA-30 reduced the regurgitant fraction to $3.87 \pm 6.79 \%$ (median, 0.009\%; IQR, 1\%-4.94\%), and adding PMA to UMA-26 resulted in a regurgitant fraction of $3.71 \pm 6.25 \%$ (median, 0 ; IQR, $0 \%-5.45 \%$ ).

\section{Tenting Geometry and Coaptation Length}

PMA significantly reduced tenting area and height, indicating that it relieved the tethering on the mitral valve as depicted in Figure 4, $B$ and $C$. At baseline, the mitral valve geometry was tuned such that the mean tenting area was minimal, at $1.56 \pm 4.92 \mathrm{~mm}^{2}$ (median, 0; IQR, 0-0). On inducing annular and subannular geometric distortions leading to FMR, the mean tenting area increased significantly to $82.64 \pm 50.48 \mathrm{~mm}^{2}$ (median, $53.43 \mathrm{~mm}^{2}$; IQR, 49.71-98.39 $\mathrm{mm}^{2}$ ). Undersizing annuloplasty to $30 \mathrm{~mm}$ decreased the mean tenting area to $58.53 \pm 42.75 \mathrm{~mm}^{2}$ (median, $61.89 \mathrm{~mm}^{2}$; IQR, 23.15-97.84 $\mathrm{mm}^{2}$ ), and further downsizing to $26 \mathrm{~mm}$ resulted in a mean tenting area of $52.28 \pm 42.41 \mathrm{~mm}^{2}$ (median, $42.27 \mathrm{~mm}^{2}$; IQR, 22.10-76.84 $\mathrm{mm}^{2}$ ). The addition of PMA to the $30-\mathrm{mm}$ 

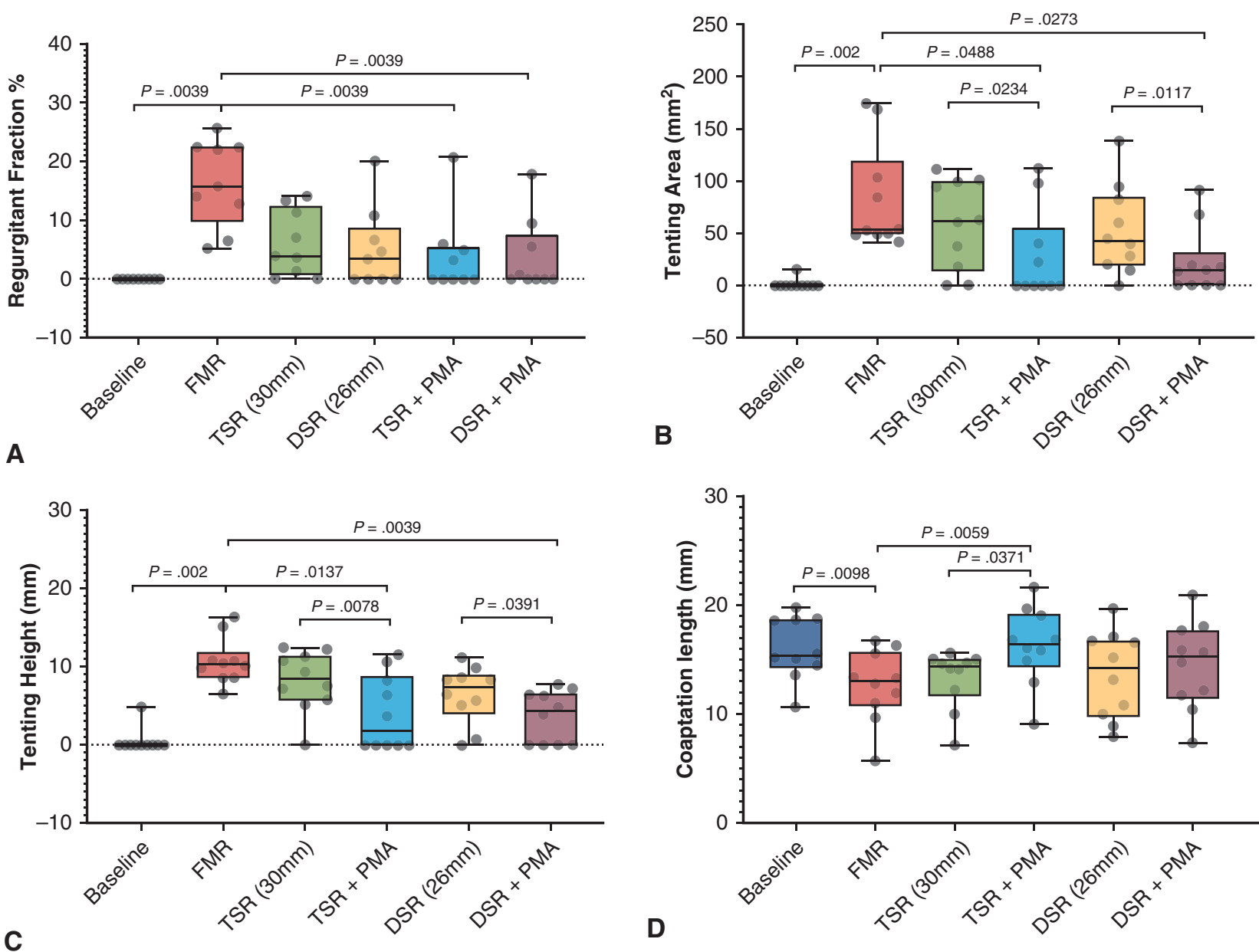

FIGURE 4. A, Changes in regurgitant fraction before and after different repairs. Undersizing mitral annuloplasty (UMA) with a 30-mm or 26-mm ring reduced the mitral regurgitation, but were not significantly different than the pre-repair condition. The addition of papillary muscle approximation $(P M A)$ after both sizes of annuloplasty reduced the regurgitant fraction significantly compared with the disease state. The regurgitation fractions after PMA were not different from the baseline/predisease state. B, The tenting area was higher in the diseased group compared with baseline, as a result of the geometric distortions imposed on the valve. After UMA, the tenting area was reduced, but was not statistically significant. With PMA, the tenting area was significantly lower than that with the corresponding annuloplasty alone and compared with the diseased state. C, Tenting height was measured at the central A2-P2 cusps; its changes under different experimental conditions are shown. Identical trends as for tenting area were observed. D, Systolic leaflet coaptation length was significantly reduced in the disease state compared with baseline. Annuloplasty did not significantly alter the leaflet coaptation length. The addition of PMA increased coaptation with the 30-mm ring but not with the 26-mm ring. In each plot, the horizontal line indicates the median, and the whiskers indicates the minimum and maximum. Groupwise comparisons were performed with one-way ANOVA, and multiple comparisons with performed with the Friedman or Wilcoxon test. FMR, Functional mitral regurgitation; TSR, true-sized ring; DSR, down-sized ring.

annuloplasty ring reduced the mean tenting area to $27.31 \pm 43.38 \mathrm{~mm}^{2}$ (median, 0; IQR, 0-35.89 $\mathrm{mm}^{2}$ ), and when used with a $26-\mathrm{mm}$ annuloplasty ring reduced the mean tenting area to $22.44 \pm 31.6 \mathrm{~mm}^{2}$ (median, $14.41 \mathrm{~mm}^{2}$; IQR, 0-18.59 $\mathrm{mm}^{2}$ ).

Similar trends were observed with tenting height (Figure 4, $C$ ), with the addition of PMA yielding the largest reduction in the tenting height. At baseline, the mean tenting height was $0.49 \pm 1.54 \mathrm{~mm}$ (median, 0; IQR, 0-0), which increased with FMR geometry to $10.73 \pm 2.96 \mathrm{~mm}$ (median, $10.28 \mathrm{~mm}$; IQR, 8.96-10.77 mm). A 30-mm annuloplasty resulted in a mean tenting height of $8.17 \pm 3.86 \mathrm{~mm}$ (median, $8.45 \mathrm{~mm}$; IQR, 6.15-
$11.07 \mathrm{~mm}$ ), and a 26-mm annuloplasty resulted in a mean tenting height of $6.45 \pm 3.69 \mathrm{~mm}$ (median, $7.42 \mathrm{~mm}$; IQR, 5.25-8.62 mm). Concomitant PMA with a $30-\mathrm{mm}$ annuloplasty ring resulted in a tenting height of $4.05 \pm 4.76 \mathrm{~mm}$ (median, $1.87 \mathrm{~mm}$; IQR, 0-7.75 mm), and PMA with a 26-mm annuloplasty ring resulted in a mean tenting height of $3.65 \pm 3.32 \mathrm{~mm}$ (median, $4.37 \mathrm{~mm}$; IQR, 0-6.415 mm). The mean systolic coaptation length (Figure $4, D$ ) at baseline was $16 \pm 2.88 \mathrm{~mm}$ (median, $15.34 \mathrm{~mm}$; IQR, 14.59-18.61 mm), which was reduced under FMR conditions to $12.62 \pm 3.31 \mathrm{~mm}$ (median, $13.02 \mathrm{~mm}$; IQR, 11.23-14.96 mm). The mean coaptation length was $13.25 \pm 2.71 \mathrm{~mm}$ (median, $14.4 \mathrm{~mm}$; IQR, 

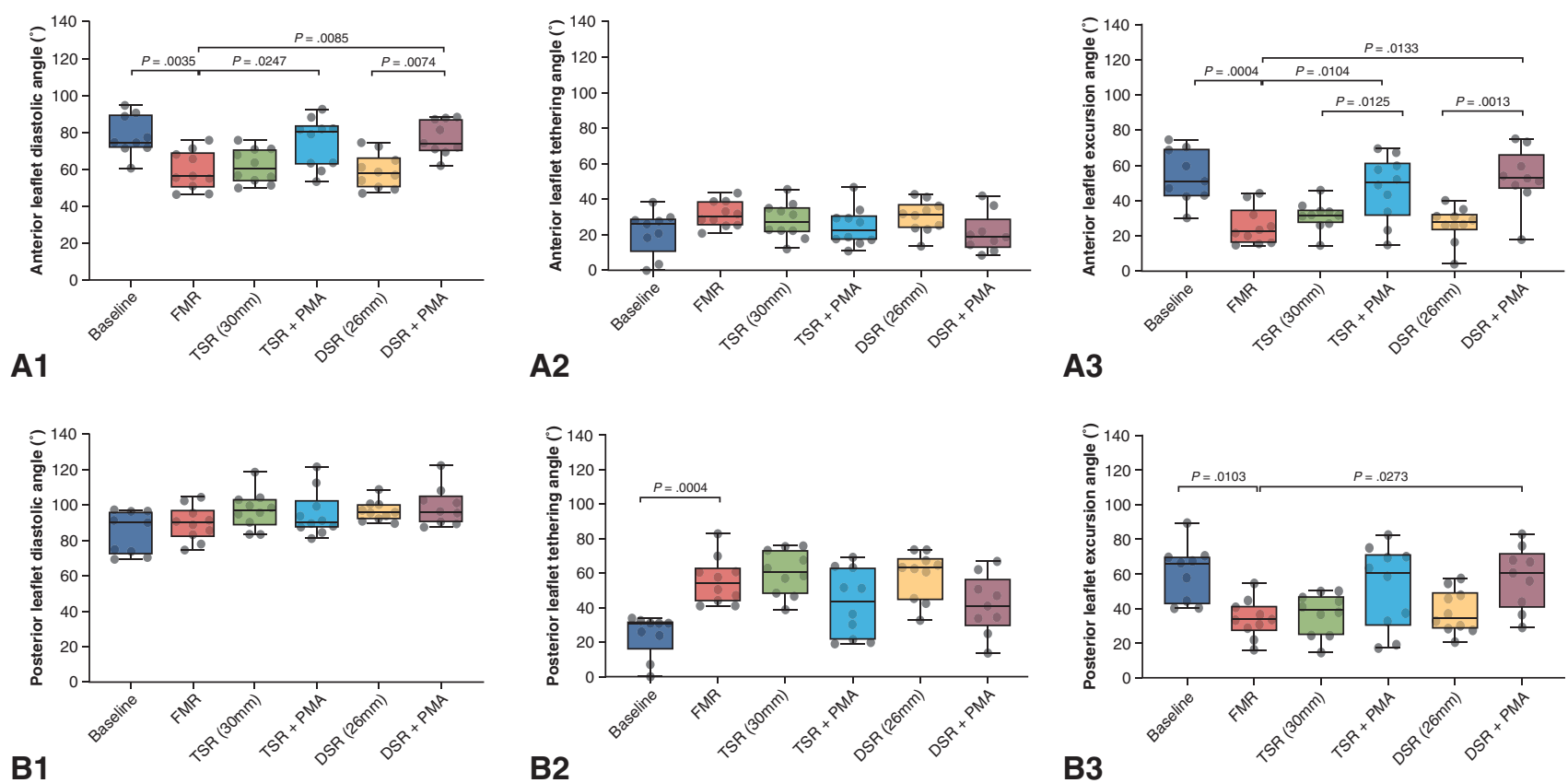

FIGURE 5. Leaflet mobility was quantified in diastole (diastolic angle) and systole (systolic angle), and the excursion angle was defined as the difference between the two. A, The anterior diastolic angle was significantly altered from baseline when functional mitral regurgitation was induced by tethering the valve. Neither true-sized nor downsized annuloplasty improved this angle. The addition of papillary muscle approximation (PMA) to annuloplasty significantly increased the diastolic angle, indicating that better valve opening was possible. The anterior systolic angle was not significantly altered in any of the groups. The anterior excursion angle was decreased in the diseased state and was not improved after annuloplasty of either size. The addition of PMA significantly improved the excursion angle. B, The posterior diastolic and systolic angles and the excursion angles were not significantly altered under the different conditions. Data are depicted in a box-and-whiskers plot. The horizontal line in each box is the median, and the 2 whiskers indicate the minimum and maximum of the distribution. FMR, Functional mitral regurgitation; TSR, true-sized ring; DSR, down-sized ring.

12.68-14.9 mm) with a 30-mm annuloplasty and $13.58 \pm 4.01 \mathrm{~mm}$ (median, $14.16 \mathrm{~mm}$; IQR, 10.2$16.65 \mathrm{~mm}$ ) with a 26-mm annuloplasty. Adding PMA resulted in a mean coaptation length of $16.26 \pm 3.55 \mathrm{~mm}$ (median, $16.44 \mathrm{~mm}$; IQR, 15.12-18.48 mm) for a $30-\mathrm{mm}$ ring and $14.45 \pm 4.05 \mathrm{~mm}$ (median, $15.22 \mathrm{~mm}$; IQR, $11.85-17.17 \mathrm{~mm}$ ) for a $26-\mathrm{mm}$ ring. Statistical comparisons of these datasets are summarized in Table 1.

\section{Mitral Valve Kinematics}

Mitral valve kinematics under each experimental condition are summarized in Figure 5. The anterior leaflet diastolic open angle was $75.21 \pm 10.5^{\circ}$ (median, $71.78^{\circ}$; IQR, 68.86-85.13 $)$ at baseline, $57 \pm 9.93^{\circ}$ (median, $53.95^{\circ}$; IQR, 50.16-64.9 $)$ with FMR geometry, $59.45 \pm 8.89^{\circ}\left(\right.$ median, $57.98^{\circ}$; IQR: 52.63-67.4 ${ }^{\circ}$ ) with a $30-\mathrm{mm}$ annuloplasty ring, and $56.78 \pm 8.95^{\circ}$ (median, 55.82 $2^{\circ}$ IQR, 49.71-61.38 ) with a 26-mm annuloplasty ring. The addition of PMA significantly increased the mean diastolic angle to $71.66 \pm 12.85^{\circ}$ (median, $77.11^{\circ}$; $\mathrm{IQR}, 61.14-78.93^{\circ}$ ) with the $30-\mathrm{mm}$ annuloplasty ring and $73.84 \pm 9.07^{\circ}$ (median, $70.96^{\circ}$; IQR, 68.12-83.4 ${ }^{\circ}$ ) with the 26-mm ring. The mean anterior leaflet systolic closed angle was $21.19 \pm 12.51^{\circ}$ (median, 25.83 ${ }^{\circ}$; IQR, 17.77$27.96^{\circ}$ ) at baseline, $31.38 \pm 7.07^{\circ}$ (median, $30.22^{\circ}$; IQR,
26.23-37.01 ${ }^{\circ}$ ) with FMR geometry, $27.96 \pm 10.12^{\circ}$ (median, $27.09^{\circ}$; IQR, $22.3-34.34^{\circ}$ ) with a $30-\mathrm{mm}$ annuloplasty ring, and $30.13 \pm 8.88^{\circ}$ (median, $31.22^{\circ}$; IQR, 24.17-35.45 ) with a 26-mm annuloplasty ring. The addition of PMA resulted in a mean anterior systolic angle of $24.59 \pm 10.67^{\circ}$ (median, $22.79^{\circ}$; IQR, $17.43-29.55^{\circ}$ ) with the $30-\mathrm{mm}$ annuloplasty ring and $20.87 \pm 11.08^{\circ}$ (median, $18.59^{\circ}$; IQR, 14.32$21.72^{\circ}$ ) with the $26-\mathrm{mm}$ ring. The mean anterior excursion angle at baseline was $54.01 \pm 15.02^{\circ}$ (median, 51.06 ${ }^{\circ}$; $\left.\mathrm{IQR}, 43.03-68.61^{\circ}\right)$ at baseline, $25.61 \pm 10.63^{\circ}$ (median, $22.73^{\circ}$; IQR, 17.21-30.6 $)$ with FMR, $31.45 \pm 7.95^{\circ}$ (median, $31.83^{\circ}$; IQR, $28.37-34.05^{\circ}$ ) with a $30-\mathrm{mm}$ annuloplasty ring, and $26.65 \pm 10^{\circ}$ (median, 27.94 ; IQR, 25.55$31.33^{\circ}$ ) with a $26-\mathrm{mm}$ ring. Adding PMA significantly increased the mean excursion angle to $47.06 \pm 18.22^{\circ}$ (me-

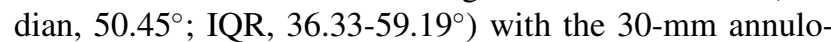
plasty ring and $52.97 \pm 16.79^{\circ}$ (median, 52.74 ; IQR, $48.69-59.32^{\circ}$ ) with the $26-\mathrm{mm}$ annuloplasty ring.

The mean posterior leaflet diastolic open angle was $84.51 \pm 11.93^{\circ}$ (median, $90.37^{\circ}$; IQR, 73.98-96.34 ${ }^{\circ}$ ) at baseline, $89.62 \pm 9.67^{\circ}$ (median, $90^{\circ}$; IQR, 84.01-94. $5^{\circ}$ ) with FMR geometry, $97.27 \pm 10.56^{\circ}$ (median: 97.3 ; IQR, 91.52-102.37 $)$ with a $30-\mathrm{mm}$ annuloplasty ring, and $96.65 \pm 5.65^{\circ}$ (median, $95.91^{\circ}$; IQR, 92.97-99.76 ${ }^{\circ}$ ) with a 26-mm annuloplasty ring. The addition of PMA 

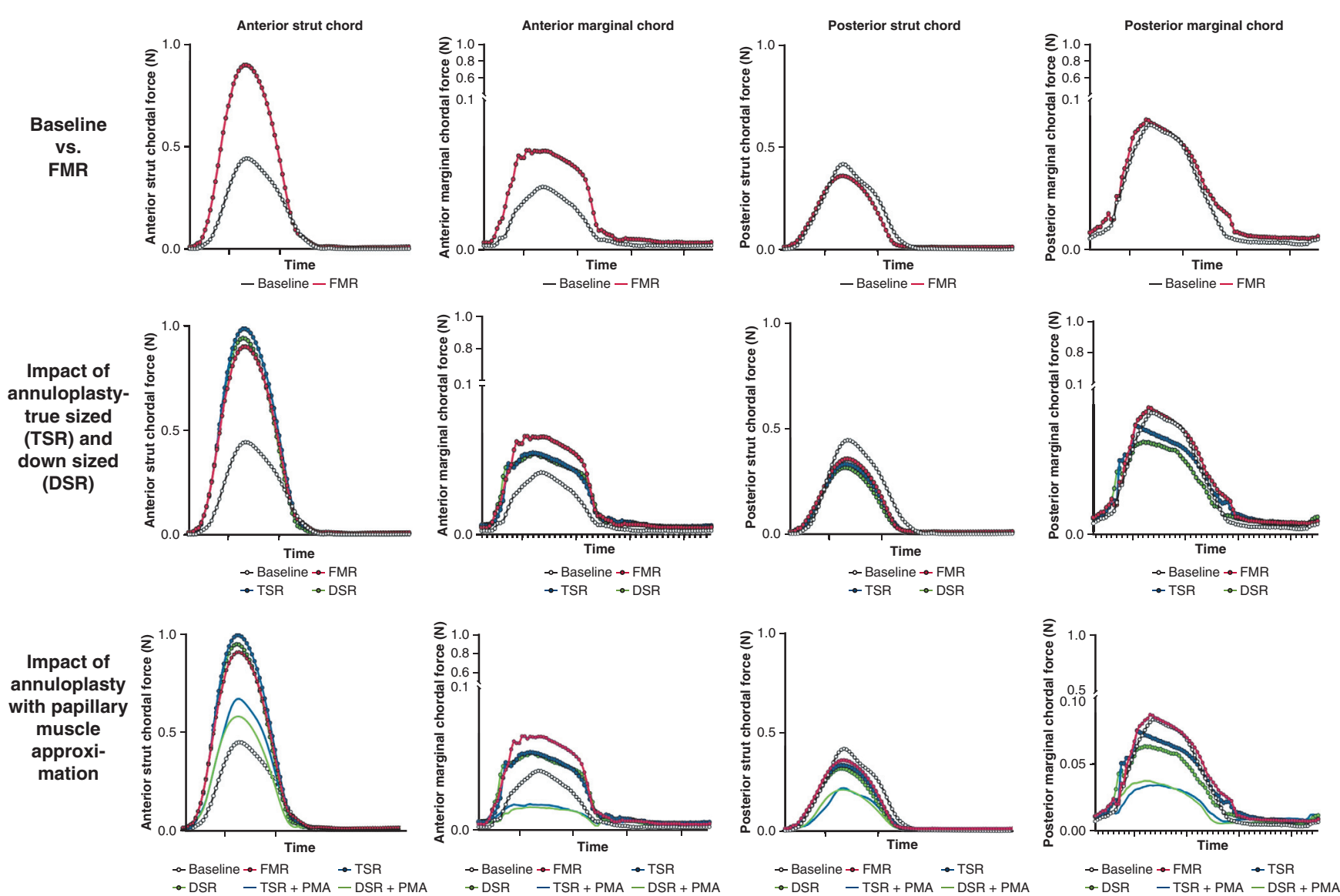

FIGURE 6. Temporal changes in chordal forces under different experimental conditions. Each trace is an average of data from 10 valves, and each valve's data is an average of 15 consecutive cardiac cycles. (Top row) Differences in the chordal forces between baseline/healthy valve configuration and the functional mitral regurgitation condition in which the mitral annulus is dilated and the papillary muscles are displaced outwardly. A significant rise in the peak force was seen in both the anterior strut and marginal chordae, but such a rise was not observed in the posterior mitral leaflet. (Middle row) The impact of mitral annuloplasty, both true-sized ring (TSR) and down-sized ring $(D S R)$. Both TSR and DSR minimally reduced the peak forces in the chordae tendineae. (Bottom row) The impact of concomitant papillary muscle approximation (PMA) on the force distribution. Adding PMA significantly reduced the peak chordal forces in all the chordae with both TSR and DSR; FMR, Functional mitral regurgitation.

significantly resulted in a diastolic angle of $95.14 \pm 12.81^{\circ}$ (median, $90.51^{\circ}$; IQR, 88.09-98.15 $5^{\circ}$ with the $30-\mathrm{mm}$ annuloplasty ring and $99.45 \pm 10.87^{\circ}$ (median, $96.54^{\circ}$; IQR, $90.86-102.47^{\circ}$ ) with the $26-\mathrm{mm}$ annuloplasty ring. The mean posterior leaflet systolic closed angle was $24 \pm 12.1^{\circ}$ (median, $30.67^{\circ}$; IQR, $23.97-31.07^{\circ}$ ) at baseline,

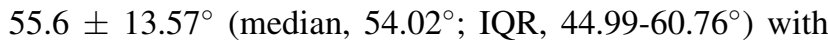
FMR geometry, $60.32 \pm 12.85^{\circ}$ (median, $60.66^{\circ}$; IQR, $50.55-71.39^{\circ}$ ) with a $30-\mathrm{mm}$ annuloplasty ring, and $30.13 \pm 8.88^{\circ}$ (median, $31.22^{\circ}$; IQR, 24.17-35.45 ${ }^{\circ}$ ) with a 26-mm annuloplasty ring. The addition of PMA resulted in a posterior systolic angle of $42.56 \pm 19.53^{\circ}$ (median, $43.71^{\circ}$; IQR, $23.8-60.32^{\circ}$ ) with the $30-\mathrm{mm}$ annuloplasty ring and $41.58 \pm 17.08^{\circ}$ (median, $41^{\circ}$; IQR, 33.79$50.83^{\circ}$ ) with the $26-\mathrm{mm}$ annuloplasty ring. The posterior leaflet excursion angle was $60.5 \pm 16.53^{\circ}$ (median,

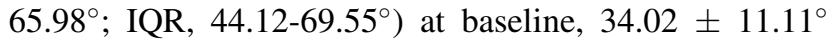
(median, $33.57^{\circ}$; IQR, 29.11-39.49 ${ }^{\circ}$ ) with FMR geometry,
$36.95 \pm 11.9^{\circ}$ (median, $39.32^{\circ}$; IQR, 27.7-45.6 ${ }^{\circ}$ ) with the $30-\mathrm{mm}$ annuloplasty ring, and $38.1 \pm 12.47^{\circ}$ (median, $34.68^{\circ}$; IQR, 28.7-47.4 ) with the $26-\mathrm{mm}$ annuloplasty ring. Adding PMA increased the mean excursion angle to $52.58 \pm 23.8^{\circ}$ (median, 60.9 ; IQR, 34.23-69.93 ${ }^{\circ}$ ) with the $30-\mathrm{mm}$ annuloplasty ring and $57.87 \pm 18.09^{\circ}$ (median, $60.51^{\circ}$, IQR, $44.03-67.84^{\circ}$ ) with the $26-\mathrm{mm}$ ring.

\section{Chordal Force Distribution}

Temporal traces of the marginal and strut chordae of the anterior and posterior mitral valve leaflets under each experimental condition are depicted in Figure 6, and the peak systolic forces are compared in Figure 7. On the anterior leaflet, the FMR geometry significantly elevated the forces in both the anterior strut and anterior marginal chordae. Undersizing the annuloplasty to $30 \mathrm{~mm}$ or $26 \mathrm{~mm}$ did not relieve these elevated systolic forces in either of the chordae. The addition of PMA significantly reduced the forces in both 
TABLE 1. Mitral valve hemodynamics, tethering geometric indices, and leaflet kinematics at baseline, after induction of FMR, and on repair with annuloplasty alone and combined with PMA

\begin{tabular}{|c|c|c|c|c|c|c|c|c|c|c|c|c|c|c|c|c|c|}
\hline Parameter & Baseline & FMR & $\begin{array}{l}P \text { value } \\
\text { vs } \\
\text { baseline }\end{array}$ & TSR & $\begin{array}{l}P \text { value } \\
\text { vs } \\
\text { baseline }\end{array}$ & $\begin{array}{l}P \text { value } \\
\text { vs FMR }\end{array}$ & DSR & $\begin{array}{c}P \text { value } \\
\text { vs } \\
\text { baseline }\end{array}$ & $\begin{array}{l}P \text { value } \\
\text { vs FMR }\end{array}$ & TSR + PMA & $\begin{array}{c}P \text { value } \\
\text { vs } \\
\text { baseline }\end{array}$ & $\begin{array}{c}P \text { value } \\
\text { vs FMR }\end{array}$ & $\begin{array}{l}P \text { value } \\
\text { vs TSR }\end{array}$ & $\begin{array}{l}\text { DSR + } \\
\text { PMA }\end{array}$ & $\begin{array}{l}P \text { value } \\
\text { vs } \\
\text { baseline }\end{array}$ & $\begin{array}{l}P \text { value } \\
\text { vs FMR }\end{array}$ & $\begin{array}{l}P \text { value } \\
\text { vs DSR }\end{array}$ \\
\hline $\begin{array}{l}\text { MR } \\
\quad \text { fraction, \% }\end{array}$ & 0 & $\begin{array}{c}16.31 \pm \\
7.33\end{array}$ & .0039 & $\begin{array}{l}6.05 \pm \\
5.63\end{array}$ & .0156 & .0547 & $\begin{array}{l}5.06 \pm \\
6.76\end{array}$ & .0312 & .762 & $3.87 \pm 6.79$ & .0625 & .0039 & .2969 & $3.71 \pm 6.25$ & . 125 & .0039 & .4688 \\
\hline $\begin{array}{l}\text { Tenting } \\
\text { area, } \mathrm{cm}^{2}\end{array}$ & $1.56 \pm 4.92$ & $\begin{array}{r}82.64 \pm \\
50.49\end{array}$ & .002 & $\begin{array}{l}58.54 \pm \\
42.76\end{array}$ & .0078 & .2324 & $\begin{array}{r}52.28 \pm \\
42.41\end{array}$ & .0039 & .1934 & $27.36 \pm 43.39$ & .125 & .0488 & .0234 & $22.45 \pm 31.6$ & .0312 & .0273 & .0117 \\
\hline $\begin{array}{l}\text { Tenting } \\
\text { height, } \mathrm{cm}\end{array}$ & $0.49 \pm 1.55$ & $\begin{array}{c}10.73 \pm \\
2.96\end{array}$ & .002 & $\begin{array}{l}8.17 \pm \\
3.86\end{array}$ & .0039 & .1309 & $\begin{array}{c}6.45 \pm \\
3.69\end{array}$ & .0039 & .0273 & $4.05 \pm 4.76$ & .0625 & .0137 & .0078 & $3.65 \pm 3.32$ & .0312 & .0039 & .0391 \\
\hline $\begin{array}{l}\text { Coaptation } \\
\text { length, } \mathrm{cm}\end{array}$ & $1.6 \pm 0.28$ & $\begin{array}{l}1.26 \pm \\
0.33\end{array}$ & .0098 & $\begin{array}{l}1.32 \pm \\
0.27\end{array}$ & .0371 & .999 & $\begin{array}{c}1.35 \pm \\
0.4\end{array}$ & .084 & .1309 & $1.62 \pm 0.35$ & .999 & .0059 & .0371 & $1.44 \pm 0.40$ & .1934 & .2637 & .4316 \\
\hline $\begin{array}{l}\text { Anterior } \\
\text { diastolic } \\
\text { angle, }^{\circ}\end{array}$ & $75.21 \pm 10.51$ & $\begin{array}{l}57 \pm \\
9.94\end{array}$ & .0035 & $\begin{array}{c}59.43 \pm \\
8.89\end{array}$ & .0161 & .9945 & $\begin{array}{c}56.79 \pm \\
8.95\end{array}$ & .003 & 9999 & $71.66 \pm 12.85$ & .9725 & .0247 & .0932 & $73.84 \pm 9.07$ & .999 & .0085 & .0074 \\
\hline $\begin{array}{l}\text { Anterior } \\
\text { systolic } \\
\text { angle, }^{\circ}\end{array}$ & $21.2 \pm 12.52$ & $\begin{array}{c}31.39 \pm \\
7.08\end{array}$ & .2611 & $\begin{array}{c}27.97 \pm \\
10.12\end{array}$ & .6945 & .9739 & $\begin{array}{c}30.13 \pm \\
8.88\end{array}$ & .4028 & .9998 & $24.6 \pm 10.67$ & .9774 & .6671 & .9753 & $20.87 \pm 1.08$ & .999 & .2303 & .3629 \\
\hline $\begin{array}{l}\text { Anterior } \\
\text { excursion } \\
\text { angle, }^{\circ}\end{array}$ & $54.02 \pm 15.03$ & $\begin{array}{c}25.62 \pm \\
10.64\end{array}$ & .0004 & $\begin{array}{c}31.46 \pm \\
7.95\end{array}$ & .0082 & .927 & $\begin{array}{c}26.66 \pm \\
10\end{array}$ & .0007 & .999 & $47.07 \pm 18.22$ & .8721 & .0104 & .1215 & $52.97 \pm 16.8$ & .999 & .0007 & .0013 \\
\hline $\begin{array}{l}\text { Posterior } \\
\text { diastolic } \\
\text { angle, }^{\circ}\end{array}$ & $84.51 \pm 11.93$ & $\begin{array}{c}89.63 \pm \\
9.67\end{array}$ & .8935 & $\begin{array}{c}97.27 \pm \\
10.57\end{array}$ & .1028 & .5811 & $\begin{array}{c}96.66 \pm \\
5.65\end{array}$ & .1358 & .665 & $95.15 \pm 12.81$ & .2505 & .8449 & .9974 & $99.45 \pm 10.88$ & .042 & .665 & .9918 \\
\hline $\begin{array}{l}\text { Posterior } \\
\text { systolic } \\
\text { angle, }^{\circ}\end{array}$ & $24.01 \pm 12.11$ & $\begin{array}{c}55.61 \pm \\
13.58\end{array}$ & .0004 & $\begin{array}{l}60.32 \pm \\
12.85\end{array}$ & $<.0001$ & .9811 & $\begin{array}{l}58.55 \pm \\
13.77\end{array}$ & $<.0001$ & 9979 & $42.57 \pm 19.54$ & .0964 & .3924 & .1066 & $41.58 \pm 17.08$ & .1505 & .9979 & .1578 \\
\hline $\begin{array}{l}\text { Posterior } \\
\text { excursion } \\
\text { angle, }\end{array}$ & $60.51 \pm 16.53$ & $\begin{array}{c}34.02 \pm \\
11.12\end{array}$ & .0103 & $\begin{array}{c}36.95 \pm \\
11.99\end{array}$ & .0303 & .9986 & $\begin{array}{c}38.11 \pm \\
12.47\end{array}$ & .0451 & .993 & $52.58 \pm 23.85$ & .8943 & .1276 & .2783 & $57.87 \pm 8.09$ & .9993 & .0273 & .1041 \\
\hline
\end{tabular}




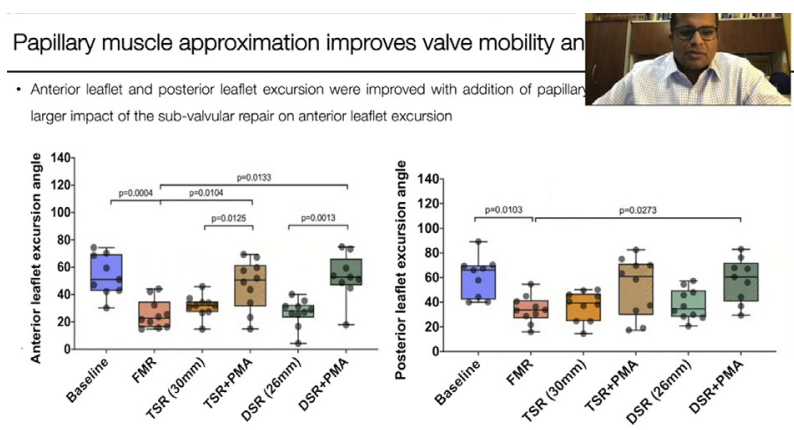

VIDEO 1. Oral narrative of the biomechanical effects of papillary muscle approximation on the mitral valve in functional mitral regurgitation. Video available at: https://www.jtcvs.org/article/S2666-2736(21)00089-9/fulltext.

chordae. In the posterior leaflet, the FMR geometry did not perturb the forces significantly in the strut or marginal chordae; however, the addition of PMA significantly reduced the forces in both posterior chordae. The mean peak force on the anterior strut chord was $0.45 \pm 0.36 \mathrm{~N}$ at baseline and increased significantly to $0.92 \pm 0.25 \mathrm{~N}$ with FMR $(P=.011)$. UMA did not reduce the peak forces, with mean values of $0.99 \pm 0.40 \mathrm{~N}$ with a $30-\mathrm{mm}$ ring and $0.95 \pm 0.33 \mathrm{~N}$ with a $26-\mathrm{mm}$ ring. Both of these peak forces were significantly higher than the baseline values $(P=.026$ and .015 , respectively). The addition of PMA reduced the mean peak force to $0.58 \pm 0.23 \mathrm{~N}$ with the 30 -mm annuloplasty ring $(P=.039$ compared to UMA-30; $P=.025$ compared to FMR) and $0.67 \pm 0.25 \mathrm{~N}$ with the $26-\mathrm{mm}$ annuloplasty ring $(P=.014$ compared to UMA-26; $P=.015$ compared to FMR). On the posterior strut chord, the mean peak force at baseline was $0.43 \pm 0.37 \mathrm{~N}$, and this remained similar at $0.36 \pm 0.25 \mathrm{~N}$ when FMR was induced. Neither annuloplasty ring altered the chordal forces, and mean peak tethering forces remained at $0.33 \pm 0.24 \mathrm{~N}$ with the $30-\mathrm{mm}$ ring and $0.32 \pm 0.22 \mathrm{~N}$ with the $26-\mathrm{mm}$ ring. The addition of PMA reduced these forces to $0.21 \pm 0.17 \mathrm{~N}$ with the $30-\mathrm{mm}$ ring and $0.22 \pm 0.18 \mathrm{~N}$ with the $26-\mathrm{mm}$ ring. In the anterior marginal chord, the mean peak force was $0.04 \pm 0.05 \mathrm{~N}$ at baseline and increased to $0.10 \pm 0.10 \mathrm{~N}$ in the disease state. A $30-\mathrm{mm}$ undersizing ring slightly reduced this peak force to $0.07 \pm 0.07 \mathrm{~N}$, and the $26-\mathrm{mm}$ ring reduced it to $0.06 \pm 0.065 \mathrm{~N}$. The addition of PMA significantly reduced this force to $0.02 \pm 0.015 \mathrm{~N}$ with the 30 -mm ring and $0.02 \pm 0.018 \mathrm{~N}$ with the 26-mm ring. On the posterior marginal chord, the mean peak force at baseline was $0.09 \pm 0.138 \mathrm{~N}$ at baseline and was increased to $0.12 \pm 0.13 \mathrm{~N}$ with FMR geometry. Annuloplasty with a $30-\mathrm{mm}$ ring did not alter the forces from the disease state, with a peak value of $0.10 \pm 0.119 \mathrm{~N}$, and with a 26-mm ring, the measured peak force was $0.07 \pm 0.09 \mathrm{~N}$. The addition of PMA reduced these peak forces to $0.043 \pm 0.034 \mathrm{~N}$ with the 30 -mm ring and $0.051 \pm 0.035 \mathrm{~N}$ with the 26 -mm ring.

\section{DISCUSSION}

The data from this study provide quantitative evidence that approximating the papillary muscles significantly reduces the tethering forces acting on the anterior and posterior leaflets in systole, thereby enabling better leaflet mobility and thus better systolic valve closure. Valve function and kinematics were significantly better with the addition of PMA to annuloplasty, than with annuloplasty alone. Furthermore, because PMA mobilized the leaflets, a better result could be achieved without severely downsizing the mitral annulus, avoiding the risk of mitral stenosis or left ventricular dysfunction, as we have recently shown to occur. $^{24}$ This simple technique of PMA reconfigures the tethered valve mechanics such that valve closure is optimized, which can yield a good outcome without the need to replace the mitral valve.

The physiological basis for PMA as an effective FMR repair stems from our work in humans that demonstrated that lateral separation of the papillary muscles in systole is a strong driver of both leaflet tenting and mitral regurgitation severity. ${ }^{3}$ Anatomically, the mitral valve receives chordae from both papillary muscles, the anterolateral and posteromedial, which insert symmetrically to both the mitral leaflets on either side of the axis that divides the valve into 2 symmetric parts. In the healthy human heart, a dynamic lateral motion exists between the papillary muscles, with a large separation in diastole and a smaller separation in systole. This lateral shortening between the muscles enables slack in the strut and marginal chordae at early systole, which allows the leaflets to move basally toward the mitral annulus and to form a large, vertical coaptation shelf. In patients with heart failure with FMR, such lateral separation between the papillary muscles in the cardiac cycle is lost, which reduces the chordal slackening, and causes the leaflets to remain tethered in early systole. Drawing the posterior annulus in the anterior direction and fixing it to a smaller rigid annuloplasty ring can lead to further increases in the tethering forces on the mitral valve chordae. Thus, coaptation is forced by the ring, but ventricular tethering forces persist.

By drawing the 2 papillary muscles together and approximating them, the lateral separation is abolished, and slackness is restored in the chordae at end diastole and early systole, as we hypothesized before and prove in this work. ${ }^{25}$ Hypothetically, this may enable better diastolic leaflet opening and provide a larger orifice for transmitral flow. As the transmitral pressure rises in the ventricle and the mitral valve begins to close, this end-diastolic and early systolic slackness may enable a higher velocity of leaflet motion toward the annulus. Thus, the leaflets may coaptate earlier in systole and may remain coaptated longer and achieve a higher coaptation length. Such a systolic configuration with a large area of coaptation is likely to dissipate chordal forces, as observed here. These mechanistic insights are summarized in Figure 8. 

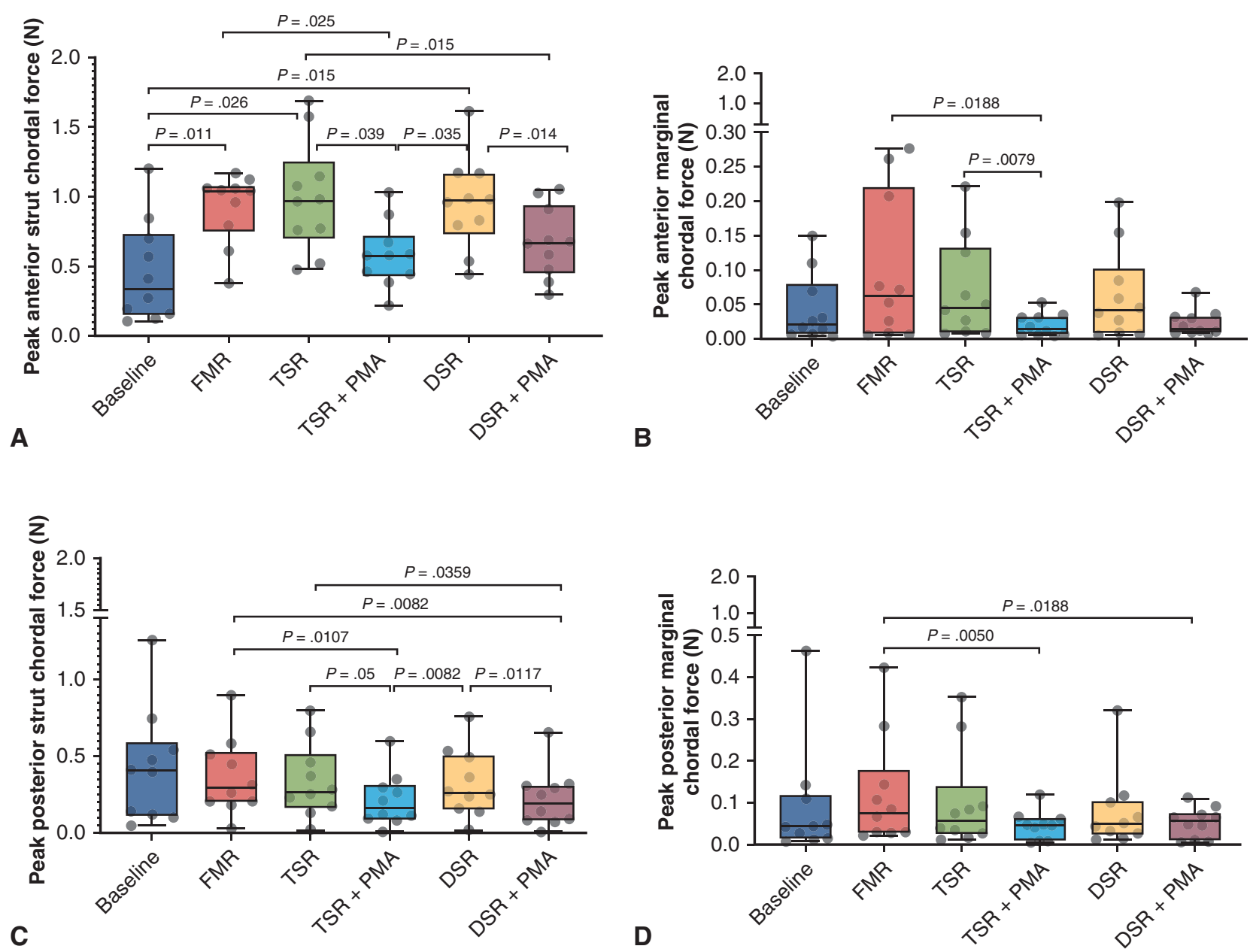

FIGURE 7. Peak systolic chordal forces under each experimental condition. A, Peak anterior strut chordal forces under different experimental conditions. The greatest reduction in the chordal forces compared with the disease state was achieved with papillary muscle approximation $(P M A)$. B, Peak posterior strut chordal forces demonstrated a significant reduction with PMA compared to the disease state and also compared to the corresponding level of annuloplasty. C, PMA reduced the anterior marginal chordal forces in some conditions but not in others. D, Peak posterior marginal chordal forces were significantly lower with PMA. FMR, Functional mitral regurgitation; TSR, true-sized ring; DSR, down-sized ring.

Clinical application of PMA requires careful analysis of the patient's anatomy. In some patients, the papillary muscles are in different planes, with one muscle retracted from the mitral annular plane more than the other. In some patients, the posteromedial papillary muscle could be scarred and shortened, and separating it from the underlying fibrotic myocardium may be risky. Patients with scarred and shortened papillary muscles are better served with other techniques than PMA. However, when the papillary muscles are in different planes, the ideal approach would be to bring their tips together into the same plane, as the chordae emerging from the muscles are of equal anatomic length. Some clinical studies have reported approximating the bases of the papillary muscles with an encircling PTFE graft, but such an approach does not yield the same result as the tip approximation. ${ }^{22,26}$ This can be attributed to the fact that basal approximation still keeps the papillary muscle tips flayed apart, resulting in persistent tethering forces on the mitral valve, as depicted in Figure E2. A modified approach is to approximate the entire lengths of the 2 papillary muscles together, or just their tips, with pledgeted Prolene sutures. Wakasa and colleagues ${ }^{23}$ tried both techniques in patients and reported that approximation of the entire length of the papillary muscle is associated with lower mortality and better durability of the repair. The mortality benefit with complete PMA is intriguing and alludes to a potential intraventricular restraining effect on the remodeling left ventricle. The effect of these techniques on ventricular remodeling warrants further study. Procedurally, accessing the papillary muscles and approximating them together would require adequate exposure, and the best incision to achieve adequate exposure requires investigation. In patients with large ventricles in which the papillary muscles are retracted out of the line 
Mitral valve function in a healthy heart with dynamic inter-papillary shortening
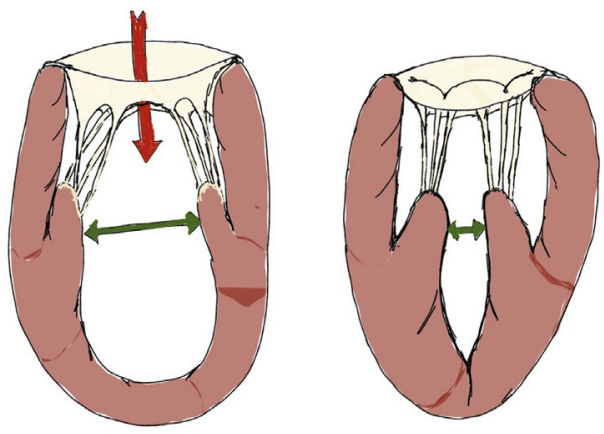

Undersizing annuloplasty in the failing heart with poor interpapillary shortening worsens leaflet tethering
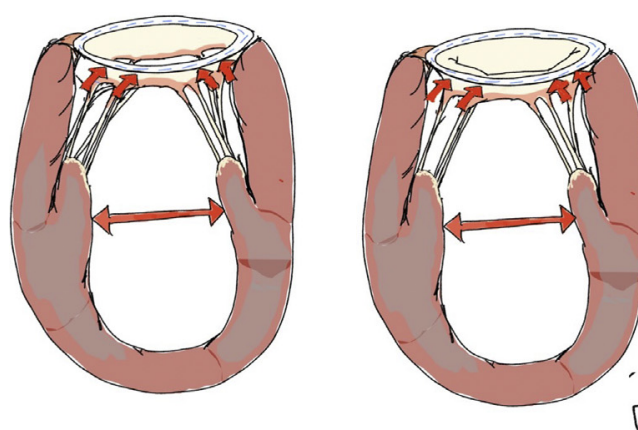

Mitral valve tethering leading to regurgitation in a failing heart with poor inter-papillary shortening
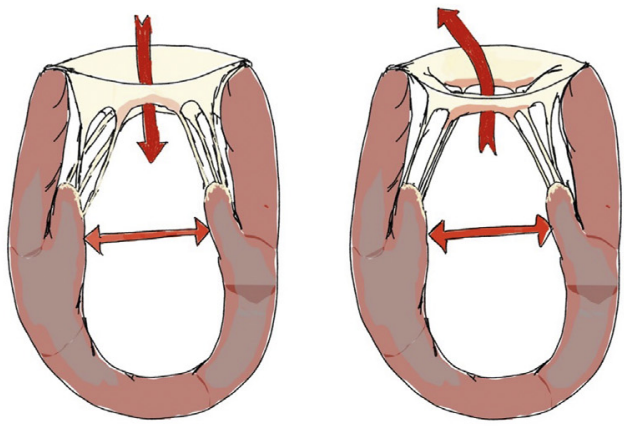

Papillary muscle approximation relieves tethering force on the leaflets in the failing heart

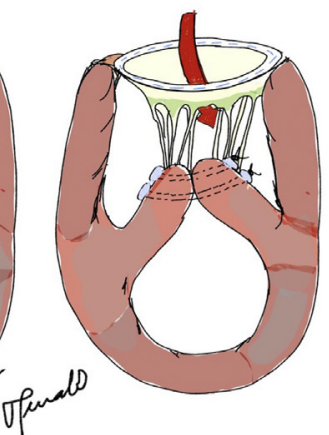

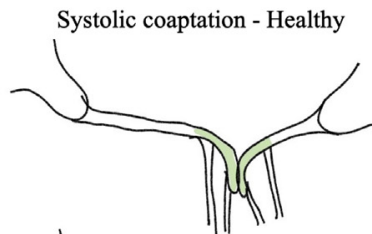

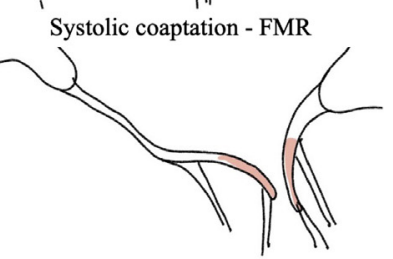

Systolic coaptation - UMA

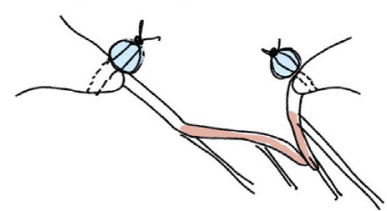

Systolic coaptation - UMA+PMA

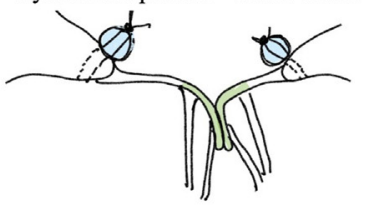

FIGURE 8. Schematic of the mechanistic basis for improved mitral valve hemodynamics and mechanics with papillary muscle approximation (PMA). A1, A healthy heart with a competent mitral valve, in which the shortening of the interpapillary muscle distance from diastole to systole enables slackness in the chordae tendineae of the mitral valve, enabling better leaflet mobility and systolic coaptation. A2, A failing and dilated heart in which poor ventricular contractility causes loss of interpapillary muscle shortening from diastole to systole. The separated papillary muscles impose a constant tethering force on the mitral valve leaflet edges in both diastole and systole. In systole, such tethering leads to loss of coaptation and mitral regurgitation. A3, On implantation of a downsizing annuloplasty ring in this heart with poor interpapillary muscle shortening, the tethering effect on the leaflets was worsened, although the smaller mitral area forced systolic leaflet coaptation. Such coaptation is not durable and leads to recurrent functional mitral regurgitation. A4, PMA relieves the tethering forces on the valve leaflets by eliminating the interpapillary muscle separation, resulting in a slackened chorda and thus leaflet free edge. This enables better mobility of the valve leaflet in systole. B, Schematic depictions of the systolic coaptation geometry under each condition. In a healthy valve, the coaptation occurs along the rough zone of the leaflet between the marginal and strut chordae. Owing to the differential elongation of the chordae in systole, the rough zone of the leaflet is verticalized and forms a nice coaptation shelf. When the annulus is dilated and the ventricle enlarged, the tethering forces on the leaflets do not allow the formation of this vertical shelf, leading to regurgitation. Annuloplasty does not address these tethering forces and thus restores a coaptation geometry that is not physiological. Adding PMA relieves these tethering forces and adequately restores coaptation of the leaflets. FMR, Functional mitral regurgitation; UMA, undersizing mitral annuloplasty.

of sight when viewed through the mitral valve, endoscopy of the ventricular chamber through the mitral valve may be useful. Another potentially useful procedural may be epicardial ultrasound to identify the papillary muscle base and heads and mark these epicardial locations. Once on cardiopulmonary bypass, depressing these regions inwardly into the ventricular cavity could bring the papillary muscle heads into view through the mitral valve. There is scope to develop surgical and percutaneous devices that can simplify this procedure tremendously, and such work is ongoing in our laboratory.

\section{Limitations}

As with any experiment, there are certain limitations that should be considered when translating the results of this work to clinical practice. First, we used an isolated mitral valve model that closely mimics mitral valve function and dysfunction but lacks a contractile and dynamic left ventricle. Because mitral valve function is impacted by left ventricular wall motion and dynamics, lack of a dynamic ventricle is a shortcoming of this model, which can be overcome in an animal model. Thus, further studies in an animal model that we reported earlier are warranted. In this mitral valve model, we use valves that are freshly acquired from healthy swine, which do not represent the fibrotic and thinned valves seen in heart failure patients with mitral regurgitation. Given that mitral valve material properties and thickness can impact force distribution, the need to repeat these studies in a relevant animal model is important. Another limitation of this work is that the 
proposed outcomes are limited to an acute experiment, and the chronic outcomes and the potential effect of continued left ventricular remodeling after the mitral valve repair were not investigated. Improved leaflet mobility and coaptation in this experiment can be extrapolated to indicate better durability, but such an extrapolation needs to be tested in an animal model and then in humans. We used a semirigid annuloplasty ring that mimics the Physio ring, but other ring types that are either partial or flexible may have different effects on the valve. Finally, we studied approximations of the entire lengths of papillary muscles, and further studies that investigate basal approximation alone and tip approximation are needed. Nonetheless, these limitations do not confound the primary finding of this study, that PMA significantly reduces the tethering forces acting on the mitral valve and enables better leaflet coaptation and mobility.

\section{CONCLUSIONS}

Based on the data from this study, we conclude that adding papillary muscle approximation to the mitral valve with moderate annular downsizing relieves tethering forces on the valve, improves leaflet mobility, and restores physiological valve function.

\section{Conflict of Interest Statement}

M.P. reported receipt of consulting fees from Heart Repair Technologies. M.P., K.S.S., E.L.S. reported stock ownership in Nyra Medical. All other authors reported no conflicts of interest.

The Journal policy requires editors and reviewers to disclose conflicts of interest and to decline handling or reviewing manuscripts for which they may have a conflict of interest. The editors and reviewers of this article have no conflicts of interest.

\section{References}

1. Levine RA, Hagége AA, Judge DP, Padala M, Dal-Bianco JP, Aikawa E, et al. Mitral valve disease-morphology and mechanisms. Nat Rev Cardiol. 2015; 12:689-710.

2. Asgar AW, Mack MJ, Stone GW. Secondary mitral regurgitation in heart failure: pathophysiology, prognosis, and therapeutic considerations. J Am Coll Cardiol. 2015;65:1231-48.

3. Kalra K, Wang Q, McIver BV, Shi W, Guyton RA, Sun W, et al. Temporal changes in interpapillary muscle dynamics as an active indicator of mitral valve and left ventricular interaction in ischemic mitral regurgitation. J Am Coll Cardiol. 2014;64:1867-79.

4. Topilsky Y, Vaturi O, Watanabe N, Bichara V, Nkomo VT, Michelena H, et al. Real-time 3-dimensional dynamics of functional mitral regurgitation: a prospective quantitative and mechanistic study. J Am Heart Assoc. 2013;2:e000039.

5. Bach DS, Bolling SF. Improvement following correction of secondary mitral regurgitation in end-stage cardiomyopathy with mitral annuloplasty. Am J Cardiol. 1996;78:966-9.

6. Green GR, Dagum P, Glasson JR, Nistal JF, Daughters GT II, Ingels NB Jr, et al. Restricted posterior leaflet motion after mitral ring annuloplasty. Ann Thorac Surg. 1999;68:2100-6.

7. Sielicka A, Sarin EL, Shi W, Sulejmani F, Corporan D, Kalra K, et al. Pathological remodeling of mitral valve leaflets from unphysiologic leaflet mechanics af- ter undersized mitral annuloplasty to repair ischemic mitral regurgitation. $J$ An Heart Assoc. 2018;7:e009777.

8. Bertrand PB, Verbrugge FH, Verhaert D, Smeets CJP, Grieten L, Mullens W, et al. Mitral valve area during exercise after restrictive mitral valve annuloplasty: importance of diastolic anterior leaflet tethering. J Am Coll Cardiol. 2015;65:452-61.

9. Gelsomino S, van Garsse L, Lucà F, Lorusso R, Cheriex E, Massimiliano Rao C, et al. Impact of preoperative anterior leaflet tethering on the recurrence of ischemic mitral regurgitation and the lack of left ventricular reverse remodeling after restrictive annuloplasty. J Am Soc Echocardiogr. 2011;24:1365-75.

10. Bothe W, Escobar Kvitting JP, Stephens EH, Swanson JC, Liang DH Ingels NB Jr, et al. Effects of different annuloplasty ring types on mitral leaflet tenting area during acute myocardial ischemia. J Thorac Cardiovasc Surg. 2011;141:345-53.

11. Bothe W, Escobar Kvitting JP, Swanson JC, Göktepe S, Vo KN, Ingels NB, et al How do annuloplasty rings affect mitral leaflet dynamic motion? Eur J Cardiothorac Surg. 2010;38:340-9.

12. Ryan LP, Jackson BM, Hamamoto H, Eperjesi TJ, Plappert TJ, St John-Sutton M, et al. The influence of annuloplasty ring geometry on mitral leaflet curvature. Ann Thorac Surg. 2008;86:749-60; discussion 749-60.

13. Kuwahara E, Otsuji Y, Iguro Y, Ueno T, Zhu F, Mizukami N, et al. Mechanism of recurrent/persistent ischemic/functional mitral regurgitation in the chronic phase after surgical annuloplasty: importance of augmented posterior leaflet tethering. Circulation. 2006;114(1 suppl):I529-34.

14. Lai DT, Timek TA, Dagum P, Green GR, Glasson JR, Daughters GT, et al. The effects of ring annuloplasty on mitral leaflet geometry during acute left ventricular ischemia. J Thorac Cardiovasc Surg. 2000;120:966-75.

15. Acker MA, Parides MK, Perrault LP, Moskowitz AJ, Gelijns AC, Voisine P, et al Mitral-valve repair versus replacement for severe ischemic mitral regurgitation. N Engl J Med. 2014;370:23-32.

16. Messas E, Guerrero JL, Handschumacher MD, Conrad C, Chow CM, Sullivan S, et al. Chordal cutting: a new therapeutic approach for ischemic mitral regurgitation. Circulation. 2001;104:1958-63.

17. Borger MA, Murphy PM, Alam A, Fazel S, Maganti M, Armstrong S, et al. Initial results of the chordal-cutting operation for ischemic mitral regurgitation. $J$ Thorac Cardiovasc Surg. 2007;133:1483-92.

18. Padala M, Gyoneva L, Yoganathan AP. Effect of anterior strut chordal transection on the force distribution on the marginal chordae of the mitral valve. $J$ Thorac Cardiovasc Surg. 2012;144:624-33.e2.

19. Kincaid EH, Riley RD, Hines MH, Hammon JW, Kon ND. Anterior leaflet augmentation for ischemic mitral regurgitation. Ann Thorac Surg. 2004;78 564-8; discussion 568.

20. Gomibuchi T, Takano T, Wada Y, Terasaki T, Seto T, Fukui D. Patch detachment after mitral valve repair with posterior leaflet augmentation: a case report. J Cardiothorac Surg. 2015;10:118

21. Kron IL, Green GR, Cope JT. Surgical relocation of the posterior papillary muscle in chronic ischemic mitral regurgitation. Ann Thorac Surg. 2002;74 600-1.

22. Hvass U, Tapia M, Baron F, Pouzet B, Shafy A. Papillary muscle sling: a new functional approach to mitral repair in patients with ischemic left ventricular dysfunction and functional mitral regurgitation. Ann Thorac Surg. 2003;75: 809-11.

23. Wakasa S, Kubota S, Shingu Y, Ooka T, Tachibana T, Matsui Y. The extent of papillary muscle approximation affects mortality and durability of mitral valve repair for ischemic mitral regurgitation. J Cardiothorac Surg. 2014;9:98.

24. Xu D, McBride E, Kalra K, Wong K, Guyton RA, Sarin EL, et al. Undersizing mitral annuloplasty alters left ventricular mechanics in a swine model of ischemic mitral regurgitation. J Thorac Cardiovasc Surg. 2020 Nov 6. Online ahead of print.

25. Padala M. Papillary muscle approximation is an anatomically correct repair for ischemic mitral regurgitation. J Am Coll Cardiol. 2016;68:1146-7.

26. Nappi F, Lusini M, Spadaccio C, Nenna A, Covino E, Acar C, et al. Papillary muscle approximation versus restrictive annuloplasty alone for severe ischemic mitral regurgitation. J Am Coll Cardiol. 2016;67:2334-46.

Key Words: mitral valve repair, annuloplasty, subannular repair, interpapillary muscle separation, secondary mitral regurgitation, ischemic mitral regurgitation, heart failure, left ventricular remodeling 

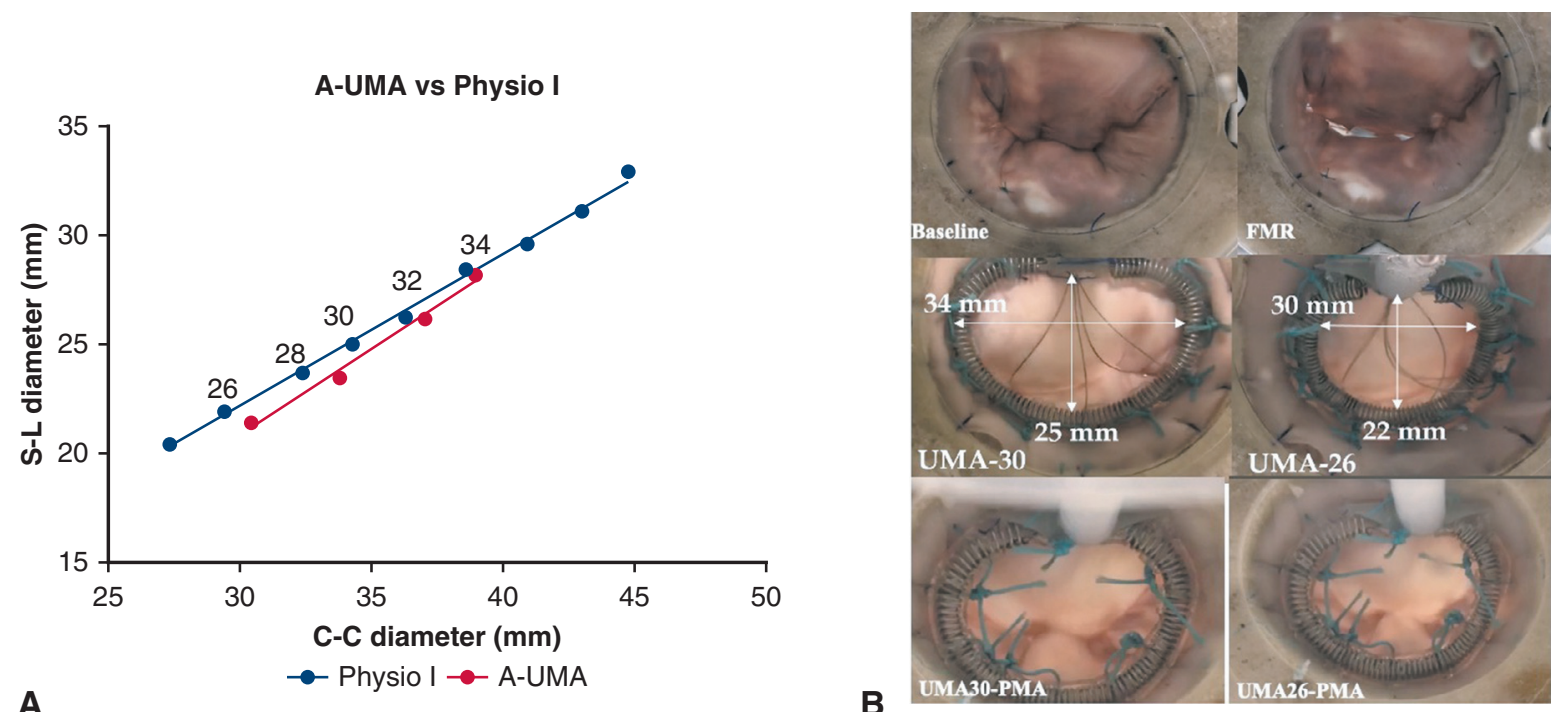

FIGURE E1. A, Equivalence between the custom-made adjustable undersizing mitral annuloplasty and different sizes of the commercial Physio annuloplasty ring (Edwards Lifesciences). B, En face view of the mitral valve at baseline after inducing functional mitral regurgitation with the 30-mm and 26-mm annuloplasty rings and after concomitant papillary muscle approximation. UMA, Undersizing mitral annuloplasty; FMR, functional mitral regurgitation; $P M A$, papillary muscle approximation.

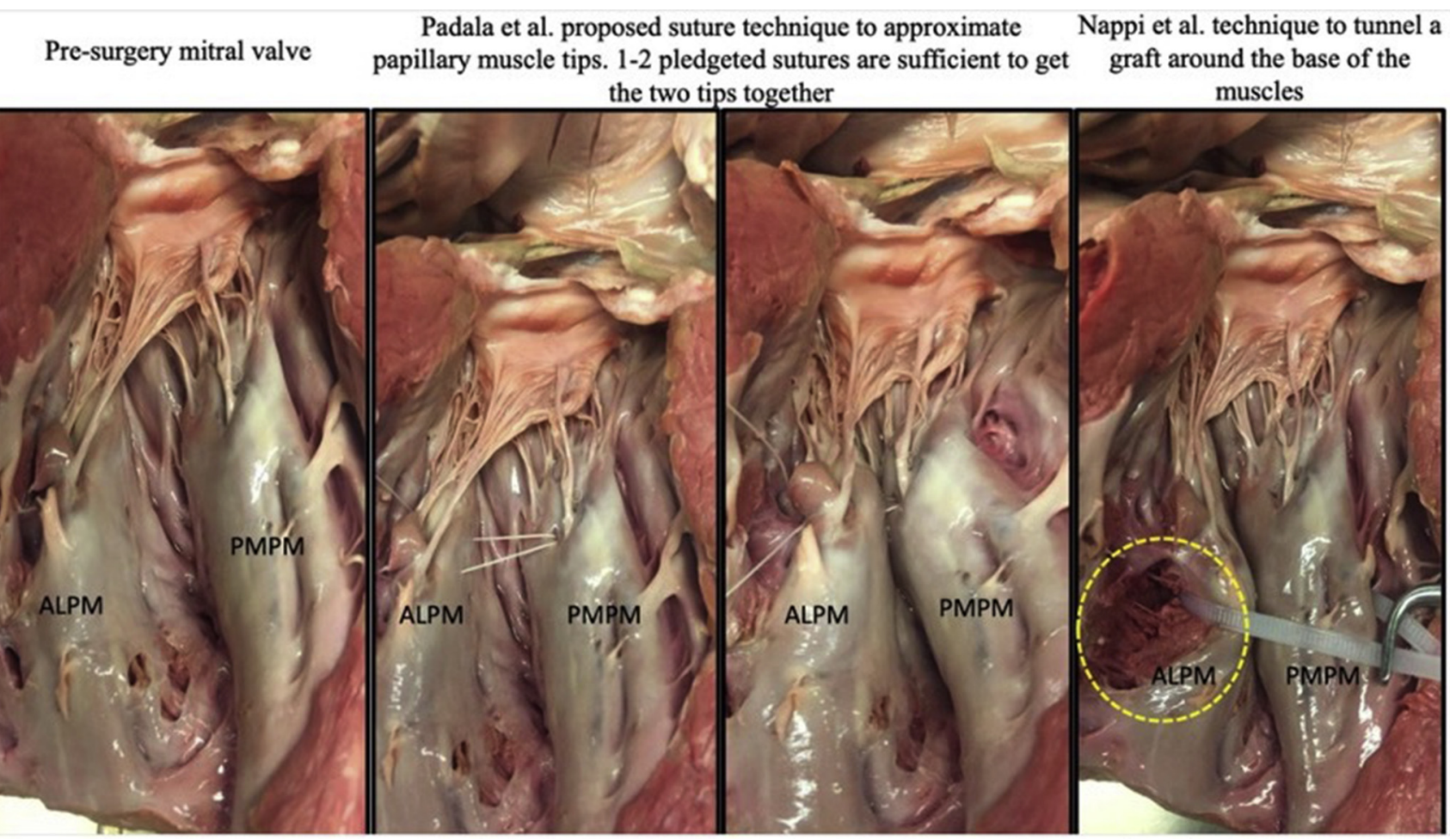

FIGURE E2. A human cadaver heart in which papillary muscle approximation (PMA) was performed at the base of the muscles and at the tip. When PMA was done at the base, the muscle tips remained flayed apart and thus did not seem to have a beneficial effect on the valve. ALPM, Antero lateral papillary muscle; $P M P M$, postero medial papillary muscle. 